\title{
指数族の分布に従う雑音下での 汎関数展開可能な系の同定
}

$\begin{array}{lllll}\text { 正員 沖 } & \text { 田 } & \text { 豪 } & \text { (山口大) } \\ \text { 正員 } & \text { 中 村 } & \text { 正 紀 } & \text { (TYSテレビ山ロ) } \\ \text { 正 } & \text { 只 } & \text { 中 } & \text { 正 吾 } & \text { (山口犬) }\end{array}$

\section{1. 緒 言}

近年，科学技術の発展や社会的要求加ら，対象上す るシステムが広範囲に及る゙につ机て，被䊒かつ多様な 非線形系を取り扱う機会が多くなっている。乙れに伴 い非線形系の同定加重要視されている。

現実には，種ヶの非線形系が存在するが，ここで は，Van der Pol 式やDuffing 式など広範な非線形录

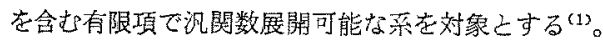

一般に，同定は入出力情報借基ついて行的れるが， その際，システムは萑音汇活されている埸合加多い。 しれまで，鞧造が未知であるシステムについて Bayes の定理に上り事後谯率を求め，システムの構造決定を 行う方法が提案されている(2)ー 観测猚至を正規分布に限定して解析されている。しか し，このBayes の定理に咕いて，観測雑音の分布は 極めて重要な役割を果している。しかも，䍒際には非 正規雜音あ多く見うりられる。例えば，レーダなごて 目慗値の位置を测定する際，距離䛊差はレイリ一分布 に徉うことが知られている(5)。よって，正磼な同定を 行うためには，奏際の雑音分布に基づいて行う必要が ある。そこで，正規赫音を含むより一般的な指数族の 分布 ${ }^{(6)}$ に良う雑音にシスデムが活されている場合を対 象とする。従来，パラメータ推定には，最尤法がよく 用いられている。しかし，てれを指数族の行布に対し て形式的に適用すると、システムとモデルの出力の偏 差が分布の檤域を超え，推定值が得ら机ない場合が

Identification of Functionally Expanded System Distorted by Noise with Exponential Family Density. By Tuyoshi Okita, Member (Faculty of Engincering, Yamaguchi University), Mascki Nakamura, Member (TYS T. V. Yamaguchi, Ltd.) \& Shyogo Tanaka, Meriber (Faculty of Engineering, Yamaguchi University).
おる。一方，システムとモデルが一致した理想状態で は，その滆差の分布は雑音の分有に等しいよ考えられ る。よって，てれらを考虑して観测值上り梮差の分布 を推定し，Kullback の情報量(7) 是最小にすることに より，パラメータを推定しよう。更化，指数挨の分布

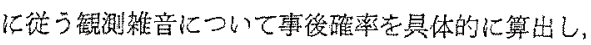
システムの構造決定を行う。また，この確率络逐次的 に与えられるため、データの增加と共によ゙のような振

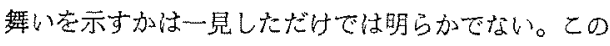
ような確率の潮近的性算について，まだ十分な考察は なされていないようである(8)。琴って，との事後確率 の渐近的性質について古考察し，本同定法の理諭的正 当性安检証する。

\section{2. 問題の設定}

対百しするシステムは，Practical 安定かつ有限項 で视関数展開可能であり，次式で与えら机る(1)、(9)。

$$
\begin{gathered}
\boldsymbol{x}(k+1)=\left(\begin{array}{c}
\boldsymbol{\theta}_{0}{ }^{T} \boldsymbol{q}_{0}(\boldsymbol{x}(k), \boldsymbol{u}(k)) \\
x(k) \\
\ldots \\
x\left(k-n_{1}+2\right)
\end{array}\right) \ldots \ldots \ldots(1) \\
\boldsymbol{x}(0)=\boldsymbol{x}_{0} \\
\boldsymbol{x}(k)=\left[x(k), x(k-1), \ldots, x\left(k-n_{1}+1\right)\right]^{T} \\
\boldsymbol{u}(k)=\left[u(k), u(k-1), \ldots, u\left(k-n_{2}+1\right)\right]^{T}
\end{gathered}
$$

ここで, $x(k)$ は $n_{1}$ 次元状態べクトル, $\boldsymbol{u}(k)$ は $n_{2}$ 次 元入力ベクトルである。广た，システムパラメータ $\theta_{0}$, および，ベクトル関数 $q_{0}(\cdot)$ は次のように定義さ 机る。

$$
\begin{aligned}
& \boldsymbol{\theta}_{0} \triangleq\left[\theta_{01}, \theta_{02}, \theta_{03}, \ldots, \theta_{0 L}\right] \ldots \ldots \ldots \\
& \boldsymbol{q}_{0}(\cdot) \triangleq\left[q_{01}(\cdot), q_{02}(\cdot), \ldots, q_{0 L}(\cdot)\right]^{T}
\end{aligned}
$$

但 $L$, 


$$
\begin{gathered}
q_{01}(\boldsymbol{z}(k)) \triangleq \prod_{h=1}^{m(l)} z_{j h(l)}(k) \quad 1 \leqq l \leqq L \\
\boldsymbol{z}(k) \triangleq\left(\boldsymbol{x}(k)^{T}, \boldsymbol{u}(k)^{T}\right)^{T}
\end{gathered}
$$

である。ここで, $m(l)$ は $\theta_{01}$ を係数とする致開項の

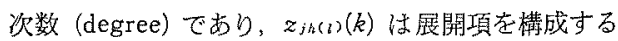
$z(k)$ の要素を表わす。また，観測方程式は次式で与え られる。

$$
y(k)=\boldsymbol{h}^{T} \boldsymbol{x}(k)+v(k) \quad k \geqq 1
$$

但し,

$$
\boldsymbol{h}^{T}=(1,0,0, \ldots, 0) ; n_{1} \text { 次元 }
$$

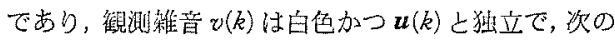
指数族 (exponential family) の密度関数を持 ${ }^{(6),(10)}$ 。

$$
\begin{aligned}
P v\left(v(k), \boldsymbol{\lambda}_{0}\right)= & \exp \left\{\boldsymbol{\phi}^{\mathrm{T}}\left(\boldsymbol{\lambda}_{0}\right) \boldsymbol{t}(v(k))-\phi\left(\boldsymbol{\lambda}_{0}\right)\right\} \\
= & \exp \left\{\boldsymbol{\phi}^{T}\left(\boldsymbol{\lambda}_{0}\right) \tau(v(k))\right. \\
& \left.+\xi\left(\boldsymbol{\lambda}_{0}\right) \ln v(k)-\phi\left(\boldsymbol{\lambda}_{0}\right)\right\} \quad(5)
\end{aligned}
$$

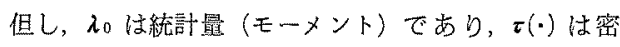

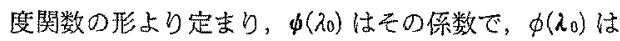
規格化定数である。また, $て(\cdot)$ は $v(k)$ の有理関数で ある。また, $P v(\cdot)$ の值域は $(-\infty, \infty)$ あるいは $[0$,

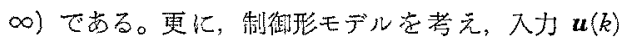
は完全観測とする。このとき，観測俌系列

$$
Y_{k}=\{y(1), u(0), y(2), \ldots, y(k), u(k-1)\}
$$

に基ついて，システムの蚟造を決定し，パラメータを 推定する問題を考える。

\section{3. システム同定}

〈3・1〉パラメータ推定 （1）式のシステムに準 じて，炊の $M$ 個のモデルを教定する。

$$
\begin{aligned}
& \boldsymbol{x}_{i}(k+1)=\left(\begin{array}{c}
\boldsymbol{\theta}_{i}{ }^{T} \boldsymbol{q}_{i}\left(\boldsymbol{x}_{i}(k), \boldsymbol{u}(k)\right) \\
x_{i}(k) \\
\ldots \\
x_{i}\left(k-n_{1 i}+2\right)
\end{array}\right) \ldots \ldots \ldots(6) \\
& \boldsymbol{x}_{i}(0)=\boldsymbol{x}_{i 0} \quad(i=1, \ldots M)
\end{aligned}
$$

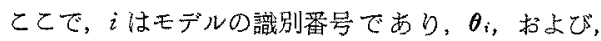
$\boldsymbol{q}_{i}(\cdot)$ は $L_{i}$ 次元である。また，モデルの出力 $y_{i}(k)$ は次式で与えられる。

$$
y_{i}(k)=\boldsymbol{h}_{i}{ }^{T} x_{i}(k)
$$

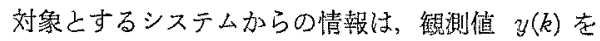
通して得られるが，y(k) は維音 $v(k)$ に污されている。 雑音の值域が $(-\infty, \infty)$ の場合, パラメー夕推定には, 最光法在用いればよい。しかし，(5)式のように雑音 の值域加半無限大の指数族の分布飞徒う埸合, 最尤法 を形式的に用いると偏差 $e_{i}(k)\left(\triangleq y(k)-y_{i}(k)\right)$ が分布

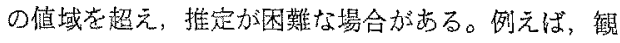
測雜音加指数分布の場合，值域を無視して対数无度関 数在最大化しようとすると占なり推定值が得られな
い。一方，システムとモデルの構造が等しい場合，そ の偏差 $e_{i}(k)$ の分布は観测雑音の分布上一致すると考 えられる。そとで，パラメータ推定の評価量上して， 新たに Kullback の情報量を導入する(7)。

$$
\begin{aligned}
& I\left(\hat{\boldsymbol{\theta}}_{i} ; \hat{\boldsymbol{\lambda}}_{i}, \boldsymbol{\lambda}_{0}\right) \\
& \quad=\int \log \{\operatorname{Pe}(\cdot) / P v(\cdot)\} \operatorname{Pe}(\cdot) d e_{i}(k) \ldots
\end{aligned}
$$

但L,

$$
\begin{aligned}
& P e(\cdot)=P e\left(e_{i}(k) ; \hat{\lambda}_{i}\right), \quad P v(\cdot)=P v\left(e_{i}(k) ; \lambda_{0}\right), \\
& e_{i}(k) \triangleq y(k)-y_{i}(k)
\end{aligned}
$$

である。ここで，統計量 $\lambda_{0}$ は

$$
\lambda_{0}=\int \boldsymbol{r}(v(k)) P v(v(k)) d v(k)
$$

であり，この推定量 $\hat{\lambda}_{i}$ は次式で与えられる。

$$
\hat{\lambda}_{i}=1 / k \cdot \sum_{k^{\prime}=1}^{k} \boldsymbol{r}_{i}\left(e_{i}\left(k^{\prime}\right)\right)
$$

但し, $\boldsymbol{r}_{i}\left(e_{i}\left(k^{\prime}\right)\right)$ は統計量 $\lambda$ ，の定義より定められる。 更に, $P e(\cdot)$ は $P v(\cdot)$ 之同じ関数形を持つ密度関数で ある。Kullback の情報量の定義より(8)式は非目て あり, $P e(\cdot)$ と $P v(\cdot)$ が一致した場合のみ，笭とな る(7)。また, $P e(\cdot)$ を $P v(\cdot)$ に近つけることは, $\varepsilon(k)$ $\triangleq x(k)-x_{i}(k)$ を確率的飞雾に近づけることを意昧す る(1)。これらより（8)式を最小にするととによりパ ラメータの推定值 $\hat{\theta}_{i}$ を得る。ここで, 各モデルどと に，無限個のデータより得られるであるうパラメータ 䑾定倌 $\theta_{i 0}$ 老若る。

$$
I\left(\boldsymbol{\theta}_{i 0}\right)=\operatorname{Min}_{\boldsymbol{\theta}_{i}} I\left(\boldsymbol{\theta}_{i} ; \lambda_{i 0}, \lambda_{0}\right)
$$

但し,

$$
\lim _{k \rightarrow \infty} \hat{\lambda}_{i}(k)=\lambda_{i 0}
$$

である。データ数が十分大なるとき， $\hat{\theta}_{i}$ は $\theta_{i 0}, \hat{\lambda}_{i}$ は $\lambda_{i 0}$ の近傍にあると期待できる。よって，(8)式を $\theta_{i}$ について痛微分し，てれを $\theta_{i 0, \lambda_{i 0}}$ のまわりでテーラ 展開する亡次式を得る。

$$
\begin{aligned}
& \left(\partial I / \partial \theta_{i}\right) \mid \begin{array}{l}
\theta_{i}=\hat{\theta}_{i} \\
\lambda_{i}=\hat{\lambda}_{i}
\end{array}
\end{aligned}
$$

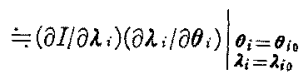

$$
\begin{aligned}
& +\left(\hat{\theta}_{i}-\theta_{i 0}\right)^{T}\left(\partial^{2} I / \partial \theta_{i}^{2}\right) \mid \begin{array}{l}
\boldsymbol{\theta}_{i=\theta_{i s}} \\
\lambda_{i}=\lambda_{i 0}
\end{array} \\
& +\left.\left(\partial I / \partial \lambda_{i}\right)\right|_{\substack{\theta_{i}=\theta_{i 0} \\
\lambda_{i}=\lambda_{i 0}}}\left(\partial \hat{\lambda}_{i} / \partial \theta_{i}-\partial \lambda_{i 0} / \partial \theta_{i}\right) \\
& +\left(\hat{\lambda}_{i}-\lambda_{i 0}\right)^{T}\left(\partial^{2} I / \partial \lambda_{i}^{2}\right) \mid \begin{array}{l}
\theta_{i}=\theta_{i 0} \\
\lambda_{i}=\lambda_{i j}
\end{array}\left(\partial \lambda_{i 0} / \partial \theta_{i}\right)
\end{aligned}
$$

ここで， $\hat{\theta}_{i}$ の最適条件より次式を得る。

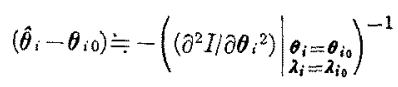




$$
\cdot\left[\left(\left(\partial I / \partial \lambda_{i}\right) \mid \begin{array}{l}
\boldsymbol{\theta}_{i}=\theta_{i 0} \\
\lambda_{i}=\lambda_{i 0}
\end{array}\right)\left\{1 / k \cdot \sum_{k^{\prime}=1}^{k}\left(\partial \boldsymbol{r}(\cdot) / \partial \theta_{i}\right)\right\}\right]^{T}
$$

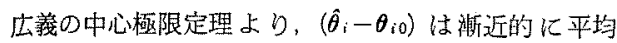
0 , 共分散 $A_{i}(k)$ の正規分布に従うこみなせる。但し， $\boldsymbol{A}_{i}(k) \triangleq \operatorname{Cov}\left(\hat{\theta}_{i}\right)$

$$
=\left(\partial^{2} I / \partial \theta_{i}{ }^{2}\right)^{-1} \sum_{i}\left(\partial^{2} I / \partial \theta_{i}{ }^{2}\right)^{-1}
$$

ここで， $\Sigma_{i}$ は次のように推定される(11)。

$$
\begin{aligned}
\Sigma_{i}=1 / k \cdot\left\{\hat{R}-\left(\partial \hat{\lambda}_{i} / \partial \theta_{i}\right)^{T}\left(\partial I / \partial \lambda_{i}\right)^{T}\right. \\
\\
\left.\cdot\left(\partial I / \partial \lambda_{i}\right)\left(\partial \hat{\lambda}_{i} / \partial \theta_{i}\right)\right\}
\end{aligned}
$$

但し，

$$
\begin{gathered}
\hat{R}=1 / k \cdot \sum_{k=1}^{N}\left\{\left(\partial I / \partial \lambda_{i}\right)\left(\partial \boldsymbol{r} / \partial \theta_{i}\right)\right. \\
\left.\cdot\left(\partial \boldsymbol{r} / \partial \theta_{i}\right)^{T}\left(\partial I / \partial \lambda_{i}\right)^{T}\right\}
\end{gathered}
$$

である。

〈3・2〉 システム構造の決定 本節では，(6)式 の侯補モデルの中加ら，最適なモデルを決定する方法 について述べる。

候補モデルが可付番かつ排反であることより, Bayes の定理を用いて, 各モデルの事徯確率 $\Pi\left(i \mid Y_{k}\right)$ を求 かることができる。

$$
\begin{aligned}
\Pi\left(i \mid Y_{k}\right)=\prod\left(i \mid Y_{k-1}\right) \\
\cdot\left(P\left(y(k) \mid i, Y_{k-1}\right) / P\left(y(k) \mid Y_{k-1}\right)\right\} \\
\Pi(i \mid 0)=1 / M \quad(i=1, \ldots M) \ldots \ldots
\end{aligned}
$$

但し,

$$
\begin{aligned}
& P\left(y(k) \mid i, Y_{k-1}\right) \\
& \quad=\int P\left(y(k) \mid i, \hat{\boldsymbol{\theta}}_{i}, Y_{k-1}\right) P\left(\hat{\boldsymbol{\theta}}_{i} \mid Y_{k-1}\right) d \hat{\boldsymbol{\theta}}_{i}
\end{aligned}
$$

$$
\begin{aligned}
& P\left(y(k) \mid Y_{k-1}\right) \\
& \quad=\sum_{i=1}^{M} I I\left(i \mid Y_{k-1}\right) P\left(y(k) \mid i, Y_{k-1}\right) \ldots
\end{aligned}
$$

である。(9)式は時刻 $k$ の推移上共に逐次計算され， この事徭確率 $\Pi\left(i \mid Y_{k}\right)$ が最大となるあのを最邀もデ ル上する。

次に(9)式を具体的に算出しよう。このためには, (10)式の皘分を実行する必要がある。デー夕数がパラ メ一夕数に比べ十分大きい場合， $\hat{\theta}_{i}$ は $\theta_{i 0}$ の近傍に あると期待でき， $P\left(y(k) \mid i, Y_{k}\right)$ の指数部を 2 次近似市 れば，積分加可能となる。ここで，v(k)の怚域が $(-\infty, \infty)$ の場合上 $[0, \infty)$ の場合の 2 つに分けて考 える。まず，値域が $(-\infty, \infty)$ の場合， $P\left(y(k) \mid i, Y_{k-1}\right)$ は次のように与えられる(12)。

$$
\begin{aligned}
P\left(y(k) \mid i, Y_{k-1}\right) & \\
= & P v\left(y(k)-y_{i}\left(k ; \theta_{i 0}\right)\right) \\
& \cdot\left|-A \Lambda_{i}+I\right|^{-1 / 2} \exp \left\{\boldsymbol{b}^{T} R^{T} \boldsymbol{b}\right\}
\end{aligned}
$$

但し,

$$
\begin{aligned}
& A=\boldsymbol{\phi}\left(\hat{\boldsymbol{\lambda}}_{i}\right)^{T}\left\{\partial \boldsymbol{t} \boldsymbol{t} / \partial \hat{\theta}_{i}{ }^{2}\right\} \\
& \boldsymbol{b}=\left\{\boldsymbol{\phi}\left(\hat{\boldsymbol{\lambda}}_{i}\right)^{T}\left(\partial \boldsymbol{t} / \partial y_{i}\right)\left(\partial y_{i} / \partial \hat{\theta}_{i}\right)\right\} \\
& R=\left(-A+\Lambda_{i}^{-1}\right)^{-1}
\end{aligned}
$$

である。次に，值域が $[0, \infty)$ の場合， $P(y(k) \mid i$, $\left.Y_{k-1}\right)$ は次のように學出される。(付録参照)

$$
\begin{aligned}
P(y(k) \mid & \left.i, Y_{k-1}\right) \\
= & \mathrm{Con} \cdot \sum_{j=1}^{l}\left[\mathrm{C}_{j} \cdot\left\{d^{l-j} \exp \left(s^{2} g^{2}\right) / d s^{l-j}\right\}\right. \\
& \left.\cdot\left\{d^{l} E f(s g) / d s^{l}\right\}\right] \quad \ldots \ldots \ldots \ldots . . .(13)
\end{aligned}
$$

但し，

$$
\begin{aligned}
\left\{d^{n} \exp \left(s^{2} g^{2}\right) / d s^{n}\right\} & =\exp \left(s^{2} g^{2}\right) g^{n} H_{n}(s g) \sum_{m=0}^{\left[\frac{n}{2}\right]}(-1)^{-n} \\
\left\{d^{n} E f(s g) / d s^{n}\right\}= & -2(-1)^{n} / \sqrt{\pi} \\
& \cdot \exp \left(-s^{2} g^{2}\right) H_{n}(s g)
\end{aligned}
$$

である。ここで，Con，および，sは分布の統計量 $\lambda_{0}$, および，惼差 $e_{i}(k)$ より定まる定数，gは まる定数であり， $H_{n}(\cdot)$ は Hermite の多項式であ

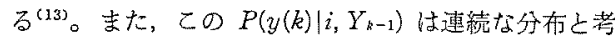
えるととができる。

以上，複数の候補モデルを与え，Bayes の定理より システムの棈造を決定する法について述べた。か し，侯補モデルをい加化設定するか力間題となる。を こで，次に，侯儶モデルの設定法について若干屍察す 子。

まず，システムの棈造に関する先験情郝が与元ら れ，構造の推測がある程度可能な場合は，推測に基つ いて複数個のモデルを設定す机ばよい。しかし，その ような先験情報がない埸合，何らかの力法でシステム を分類し，その备分類に属する代表的なモデルの適合 性を考慮して，侯補モデルを設定する方法が抆えられ る。また，システムの分類法については，システムが 沉閔数展開可能という条件の下で展開項の振幅力问の 次数 (degree) $m$, 括上び，時間方向 $D$ 次数 (order) $n 1, n 2$ によシステムを分類する方法が考艺られる(2)。

〈3.3〉事後確率の漸近的性質 システムと同し 橉造を持つモデルを $i$ ，他のモデル $j(j=1, \cdots M, j \neq i)$

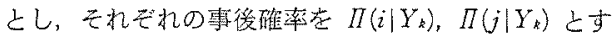
る。これらについて，次の最を定義する。

$$
\begin{aligned}
\alpha_{i j}(k) & \triangleq 1 / k \cdot \log \left\{\Pi\left(i \mid Y_{k}\right) / \Pi\left(j \mid Y_{k}\right)\right\} \\
& =1 / k\left[\sum _ { k ^ { \prime } = 1 } ^ { k } \operatorname { l o g } \left\{P_{i}\left(y\left(k^{\prime}\right) / P_{j}\left(y\left(k^{\prime}\right)\right\}\right]\right.\right.
\end{aligned}
$$

但し,

$$
\begin{aligned}
& P_{i}(y(k)) \triangleq P\left(y(k) \mid i, Y_{k-1}\right), \\
& P_{j}(y(k)) \triangleq P\left(y(k) \mid j, Y_{k-1}\right)
\end{aligned}
$$


である。との $\alpha_{i j}(k)$ の漸近的振舞いから事後確率の 潮近的性賀空知ることができる。

$k$ が十分大きい場合，パラメー多の推定䛧 $\hat{\theta}_{i}$ は平 均 $\theta_{i 0}$ ，共分散 $A_{i}(k)$ なる正瞡分布儿従う之考无引れ る。また， $A_{i}(k)$ は $k^{-1}$ のオーダを持つので 度関数は次のようになる。

$$
\lim _{k \rightarrow \infty} P\left(\hat{\boldsymbol{\theta}}_{i} \mid Y_{k-1}\right)=\delta\left(\hat{\boldsymbol{\theta}}_{i}-\boldsymbol{\theta}_{i 0}\right)
$$

こてで, $\delta(\cdot)$ はデルタ関数である。よって, $P(y(k) \mid i$, $\left.Y_{k-1}\right)$ 次の上うに近似される。

$$
\begin{aligned}
P\left(y(k) \mid i, Y_{k-1}\right) & \doteqdot P v\left(y(k) \mid \theta_{i 0}, Y_{k-1}\right) \\
& =P v\left(y(k)-y_{i 0}(k)\right) \ldots
\end{aligned}
$$

とれより，任意の小さね正の数 $\varepsilon_{1}, \varepsilon_{2}$ に対して，す心゙ ての $k \geqq k_{0}$ について

$$
\begin{array}{r}
\left|P_{i}(y(k))-P v\left(y(k)-y_{i 0}(k)\right)\right| \\
\mid P v\left(y(k)-y_{i 0}(k)\right)<\varepsilon_{1} \\
\left|P_{j}(y(k))-P v\left(y(k)-y_{j o}(k)\right)\right| \\
\mid P v\left(y(k)-y_{j 0}(k)\right)<\varepsilon_{2}
\end{array}
$$

となるランダムな正の整数 $k_{0}$ が存在する。また， $P_{i}(y(k)), P_{j}(y(k))$ は值域に招いて連続関数であり, $0<$ $P_{i}(y(k))<\infty, 0<P_{j}(y(k))<\infty$ である。よって,

$0<P_{i}(y(k)) / P_{j}(y(k))<\infty$

である。これより $\log \left\{P_{:}(y(k)) / P_{j}(y(k))\right\}$ は連綕かつ 有限な関数である己考えられる。(17)式上り，次の不 等式力得られる。

$$
\begin{aligned}
& \log [\left\{P v\left(y(k)-y_{i 0}(k)\right)\left(1-\varepsilon_{1}\right)\right\} \\
&\left./\left\{P v\left(y(k)-y_{j 0}(k)\right)\left(1+\varepsilon_{2}\right)\right\}\right] \\
&< \log \left[P_{i}(y(k)) / P_{j}(y(k))\right]< \\
& \log \left[\left\{P v\left(y(k)-y_{i 0}(k)\right)\left(1+\varepsilon_{1}\right)\right\}\right. \\
&\left./\left\{P v\left(y(k)-y_{j 0}(k)\right)\left(1-\varepsilon_{2}\right)\right\}\right]
\end{aligned}
$$

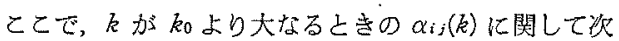
の量を考える。

$$
\lim _{k \rightarrow \infty} 1 /\left(k-k_{0}+1\right) \cdot \sum_{k^{\prime}=k_{0}}^{k} \log \left[P_{i}\left(y\left(k^{\prime}\right)\right) / P_{j}\left(y\left(k^{\prime}\right)\right)\right]
$$

ここで, $\log \left\{P_{i}(y(k)) / P_{j}(y(k))\right\}$ 你邀続であり, $\lim _{k \rightarrow \infty} 1 /$ $\left(k-k_{0}+1\right) \cdot \sum_{k^{\prime}=k_{0}}^{k}$ は平均の意味を持つ。よって，上式 化次のように衤き換えられる。

$$
\int\left\{\log \left\{P_{i}(y(k)) / P_{j}(y(k))\right\} \cdot P v\left(y(k)-y_{i 0}(k)\right)\right] d y(k)
$$

とれを(18)式の関係䘮代入すると，次の不等式が得ら れる。

$$
\begin{aligned}
& \beta_{i j}+\log \left\{\left(1-\varepsilon_{1}\right) /\left(1+\varepsilon_{2}\right)\right\} \\
& <\lim _{k \rightarrow \infty} \alpha_{i j}(k)< \\
& \quad \beta_{i j}+\log \left\{\left(1+\varepsilon_{1}\right) /\left(1-\varepsilon_{2}\right)\right\}
\end{aligned}
$$

但し,

$$
\begin{gathered}
\beta_{i j} \triangleq \int \log \left[P v_{i}(\cdot) / P v_{j}(\cdot)\right] P v_{i}(\cdot) d y(k) \\
\left.P v_{i}(\cdot) \triangleq P v_{(y}(k)-y_{i 0}(k)\right) \\
P v_{j}(\cdot) \triangleq P v\left(y(k)-y_{j}(k)\right)
\end{gathered}
$$

である。ここで， $\beta_{i j}$ は Kullback の情報量であり， これに関する定理より正である。更に，小さな正の数

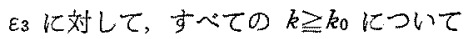

$$
\left|\alpha_{i j}(k)-\beta_{i j}\right|<\varepsilon_{3}
$$

となるランダムな正の整数 $k_{0}$ が存在する。但し、

$$
\begin{aligned}
\varepsilon_{3}= & \operatorname{Max}\left\{\left|\log \left\{\left(1-\varepsilon_{1}\right) /\left(1+\varepsilon_{2}\right)\right\}\right|,\right. \\
& \left.\left|\log \left\{\left(1+\varepsilon_{1}\right) /\left(1-\varepsilon_{2}\right)\right\}\right|\right]
\end{aligned}
$$

である。よって， $\alpha_{i j}(k)$ の定美を(20)式に代入し整理 すると次式を得る。

$$
\Pi\left(i \mid Y_{k}\right) / \Pi\left(j \mid Y_{k}\right)>\exp \left\{k\left(-\varepsilon_{3}+\beta_{i j}\right)\right\}
$$

$k$ 多十分大き場合, $-\varepsilon_{3}+\beta_{i j}>0$ 上り

$$
\begin{array}{r}
\lim _{k \rightarrow \infty}\left\{I\left(i \mid Y_{k}\right) / \Pi\left(j \mid Y_{k}\right)\right\}=\infty \\
(j=1, \ldots M, i \neq j) \quad \ldots \ldots .
\end{array}
$$

上なる。一方，磪率は次の条件を满たす必要がある。

$$
0 \leqq \Pi\left(j \mid Y_{k}\right) \leqq 1 \quad(j=1, \ldots M)
$$

$$
\sum_{j=1}^{M} \Pi\left(j \mid Y_{k}\right)=1
$$

よって，上式および(21)式より次式が得られる。

$$
\lim _{k \rightarrow \infty}\left\{1 / \|\left(j \mid Y_{k}\right)\right\}=\infty \quad(j=1, \ldots M, j \neq i)
$$

徉って，上式招よび(22)式より次の結果加得られる。

$$
\begin{aligned}
& \lim _{k \rightarrow \infty} \Pi\left(j \mid Y_{k}\right)=0 \quad(j=1, \ldots M, j \neq i) \\
& \lim _{k \rightarrow \infty} \Pi\left(i \mid Y_{k}\right)=1 \quad \ldots \ldots \ldots \ldots \ldots \ldots \ldots
\end{aligned}
$$

これより，データ数の堌加と其にシステムと同じ構造 を持つモデルの碓率が 1 亿，他のモデルの確率が沉 漸近する。よって、システムの構造を明陮に識別する ことが可能である。

\section{4. 実験的考察}

〈4・1〉 シミュレーションの概要 本方法の理論 的正当性を検証するためにディジタル・シミュレーシ ョンを行った。ここでは，工学，生物，経済などの分 野でよく用いられる双線形系，および，非線形振動を 表わす Duffing 形系を対象とし，(1)〜(4)式の定

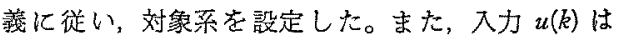
$N[0,1]$ なる正規乱数を用いた。ここで，刘秘系の システムパラメータ $\theta_{0}$ と構造を示すベクトル関数 $\boldsymbol{q}_{0}(\cdot)$ 仗次のとるりである。

(1) 双線形系

$$
\boldsymbol{q}_{0}(\cdot)=[x(k), x(k-1), u(k), x(k) u(k)]^{T}
$$


$\theta_{0}=[0.4,-0.3,1.0,-0.8]^{T}$

(2) Duffing 形采

$$
\begin{aligned}
& \boldsymbol{q}_{0}(\cdot)=\left(x(k), x(k-1), u(k), x(k)^{2}, x(k)^{3}\right)^{T} \\
& \theta_{0}=(0.3,-0.7,1.0,0.2,0.02)^{T}
\end{aligned}
$$

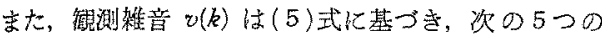
密度関数を持つ白色で $u(k)$ と独立なむのを用いた。

(a) 正婗分布

$$
\begin{aligned}
& P v(v(k))=1 /\left(\sqrt{2 \pi} \lambda_{2}\right) \cdot \exp \left\{-\left(v(k)-\lambda_{1}\right)^{2} /\left(2 \lambda_{2}\right)\right\} \\
& \quad(-\infty<v(k)<\infty)
\end{aligned}
$$

(b) 指数分布

$$
P v(v(k))=\lambda_{1} \exp \left\{\lambda_{2} v(k)\right\} \quad(0 \leqq v(k)<\infty)
$$

(c) ガンマ分布

$$
P v(v(k))=\lambda_{1} \lambda_{2} v(k) \lambda_{z}-1 / \Gamma\left(\lambda_{2}\right) \cdot \exp \left\{-\lambda_{1} v(k)\right\}
$$$$
(0 \leqq v(k)<\infty)
$$

(d) $\chi^{2}$ 分有

$$
\begin{aligned}
P v(v(k))= & (v(k) / 2) \lambda_{2} / 2-1 /\left\{2 \Gamma\left(\lambda_{1} / 2\right)\right\} \\
& \cdot \exp \{-v(k) / 2\} \quad(0 \leqq v(k)<\infty)
\end{aligned}
$$

(e) レイリー分拉

$$
P v(v(k))=2 v(k) / \lambda_{1}^{2} \cdot \exp \left\{-v(k) / \lambda_{1}^{2}\right\}
$$

$(0 \leqq v(k)<\infty)$

システムの構造を決定する際，システムに類似した モデルほど識別が難しいと考えられる。そこで，ここ では，システムと同じ構造を持つモデル，低次の構造 のモデル，および，圥長な構造のモデル設定し， シ ミュレーションを行った。具体的には，(1)，(2)0 システムに対して，それぞれ次のモデルを設定した。 双線形系汇対するモデル

$$
\begin{aligned}
& \text { モデル } 1 \\
& q_{1}=\left(x_{1}(k), u(k)\right]^{T} \\
& \text { モデル } 2 \\
& q_{2}=\left[x_{2}(k), x_{2}(k-1), u(k)\right]^{T} \\
& \text { モデル } 3 \\
& q_{3}=\left\{x_{3}(k), x_{3}(k-1), u(k), x_{3}(k) u(k)\right]^{T} \\
& \text { モデル } 4 \\
& q_{4}=\left[x_{4}(k), x_{4}(k-1), u(k), x_{4}(k) u(k), x_{4}(k)^{2}\right]^{T} \\
& \text { モデル } 1 \\
& q_{1}=\left[x_{2}(k), x_{1}(k-1), u(k)\right]^{T} \\
& \text { モデル } 2 \\
& q_{2}=\left[x_{2}(k), x_{2}(k-1), u(k), x_{2}(k)^{2}\right]^{T} \\
& \text { モデル } 3 \\
& q_{3}=\left(x_{3}(k), x_{3}(k-1), u(k), x_{3}(k)^{2}, x_{3}(k)^{3}\right)^{T} \\
& \text { モデル } 4 \\
& q_{4}=\left(x_{4}(k), x_{4}(k-1), u(k), x_{4}(k)^{2},\right. \\
& \left.x_{4}(k)^{3}, x_{4}(k) x_{4}(k-1)\right)^{T} \\
& \text { モデル5 }
\end{aligned}
$$

$$
\begin{aligned}
q_{5}= & \left\{x_{5}(k), x_{5}(k-1), u(k), x_{5}(k)^{2}, x_{5}(k)^{3},\right. \\
& \left.x_{5}(k) x_{5}(k-1), x_{5}(k)^{2} x_{5}(k-1)\right\}^{T}
\end{aligned}
$$

各モデルのパラメータ $\theta_{i}$ は， $\boldsymbol{q}_{i}$ と同次元であり (8)式の秤価関数を最小にすることにより求めた。

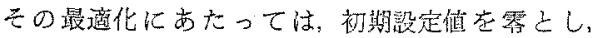

Fletcher-Powell 法葲用いた ${ }^{(14)}$ 。

〈4.2〉 シミュレーションの結果と考察 前節の シミュレーションの結果について䢞へ，考察を加える。 各々の尔布の観測維音に対して各モデルの㧱後確率

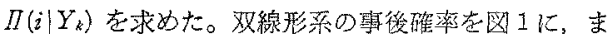
た，Duffing 形系の確率を罒2 に示するこれらの戍よ り，双線形系，Duffing 形系いずれの塄合も次の上う なことが䓂える。デー夕数が此較的少ないとき，双線 形系で䠐測雑音加 $\chi^{2}$ 分布，执よび，ガンマ分布の場 合，高次のモデルを選定している屯のがあるが，全体 としては，低次のモデルを選定する傾间がある。更 に，データ数が增加する上正しい楧造を持つモデルの

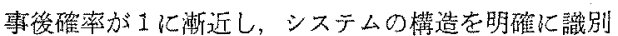
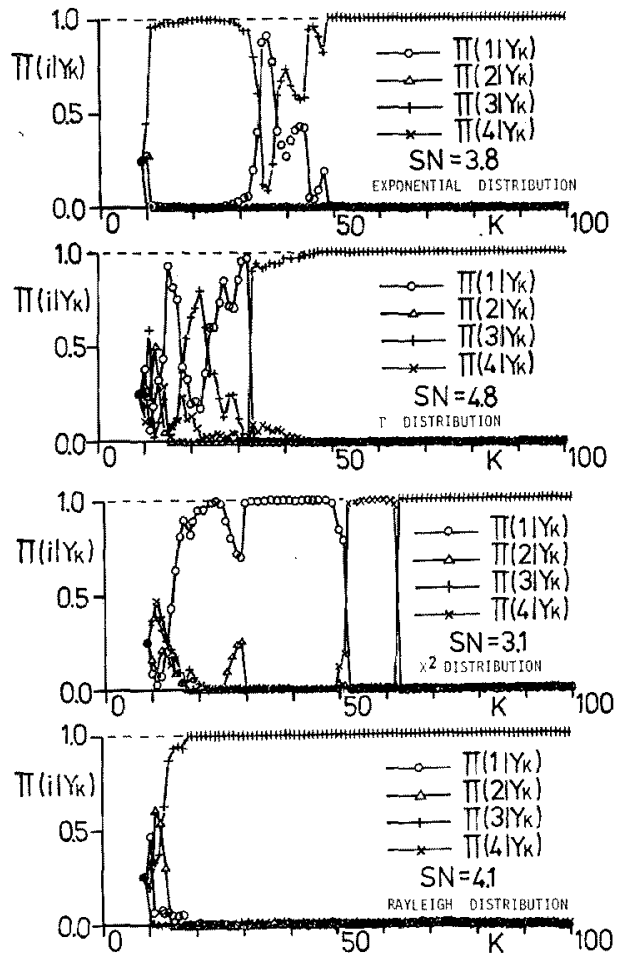

图 1 双線形系の事挠確率 $\Pi\left(i \mid Y_{k}\right)$ 一例

Fig. 1. A posteriori probability for bilinear system. 


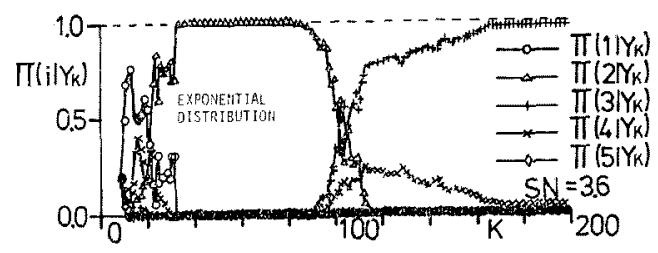

表 1 モデルの予測䛦差 $J$

Table 1. Predicted error of modeles, J.

Duffing 形系

指数分布 $\mathrm{SN}=3.6$

\begin{tabular}{l|r|r|r}
\hline 区間 & $10 \sim 21$ & $22 \sim 107$ & $108 \sim 200$ \\
\hline モデル1 & 06.64 & 113.72 & 71.35 \\
モデル2 & 14.92 & 027.86 & 10.31 \\
モデル3 & 35.15 & 115.30 & 05.56 \\
モデル4 & 56.60 & 93.85 & 5.57 \\
モデル5 & 266.78 & 87.50 & 5.57 \\
\hline
\end{tabular}

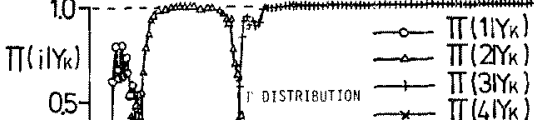

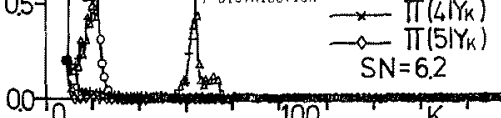

ガンマ分布 $\mathrm{SN}=6.2$

\begin{tabular}{l|r|r|r|r}
\hline 区 間 & $10 \sim 19$ & $20 \sim 36$ & $\# 37 \sim 63$ & $64 \sim 200$ \\
\hline モデル1 & 04.76 & 45.74 & 44.91 & 87.55 \\
モデル2 & 5.20 & 06.78 & 012.98 & 13.92 \\
モデル 3 & 22.54 & 9.05 & 0.70 & 01.35 \\
モデル4 & 469.26 & 10.24 & 1.96 & 1.38 \\
モ゙゙ル5 & $1.04 \times 10^{5}$ & 33.70 & 2.03 & 1.51
\end{tabular}

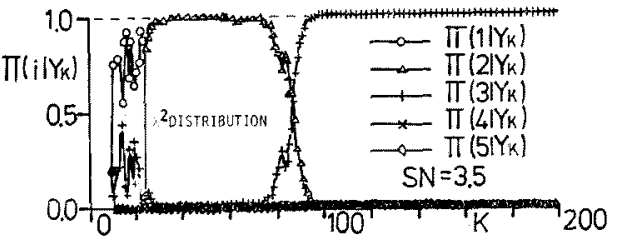

$x^{2}$ 分存 $\mathrm{SN}=10.4$

\begin{tabular}{|c|c|c|c|c|}
\hline 区 間 & $10 \sim 14$ & $19 \sim 32$ & $\# 33 \sim 57$ & $58 \sim 200$ \\
\hline モデル1 & (d) 3.91 & 4.003 & 84.71 & 88.38 \\
\hline モジル2 & 10,20 & 0.182 & fo 13.89 & 15.18 \\
\hline モデル 3 & 26.74 & 0.183 & 1.62 & 0.42 \\
\hline モデル 4 & 19.83 & 0.398 & 21.54 & 0.34 \\
\hline モデル5 5 & 17.20 & 0.485 & 23.26 & 0.34 \\
\hline \multicolumn{5}{|c|}{ レイリー分看 $\quad \mathrm{SN}=8.3$} \\
\hline 区 間 & $10 \sim 13$ & $\# 14 \sim 26$ & $27 \sim 77$ & $78 \sim 200$ \\
\hline モデル 1 & b 1.23 & 6. 34 & 88.53 & 84.75 \\
\hline $\boldsymbol{E} \overrightarrow{\boldsymbol{T}} ル 2$ & 1.91 & 0.65 & [0 19.07 & 11.54 \\
\hline モデル 3 & 203.06 & (2) 2.42 & 54.47 & 01.56 \\
\hline モ゙゙ル 4 & 633.51 & 0.34 & 56.41 & 1.56 \\
\hline モ゙フル 5 & 1064.05 & 0.34 & 81.47 & 1.41 \\
\hline
\end{tabular}

図 2 Duffing 系の事後確率 $I\left(i \mid Y_{k}\right)$ 一一例

Fig. 2. A posteriori probability for Duffing system.

している。これは，〈3・3〉節で考察した事後確率の潮 近的性留とも一致している。

またデータ数わ゙少ない埸合に選定されたモデルの 妥当性を確認するために，次の星 $J$ を導入する。

注）区間できは谓渡状態を裴わす。 ○は確率が琵大のモデル等わす。

$$
J \triangleq \Sigma\left\{x(k)-x_{i}(k \mid k-1)\right\}^{2}
$$

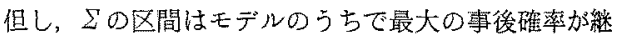
続している区間であり，過渡状態之は確率最大のモデ ルが移り変わる区間である。このJは予測望差であ
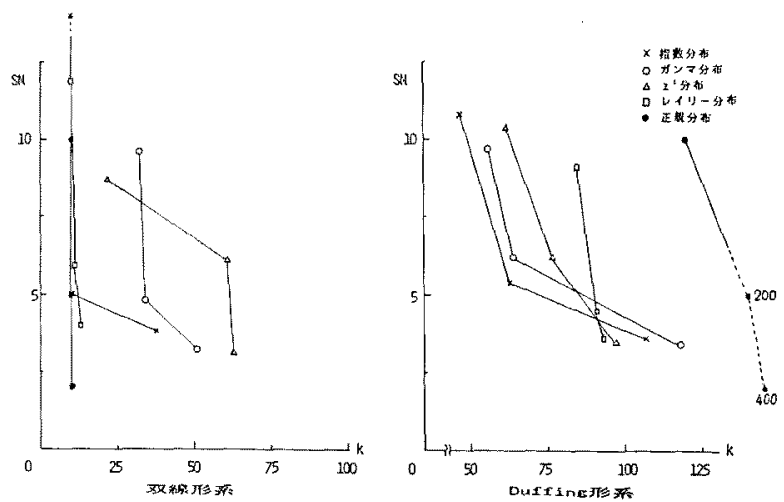

図 3 システム精造の識别化姴したデータ数の一例

Fig. 3. An example of data for descriminating system structure. 


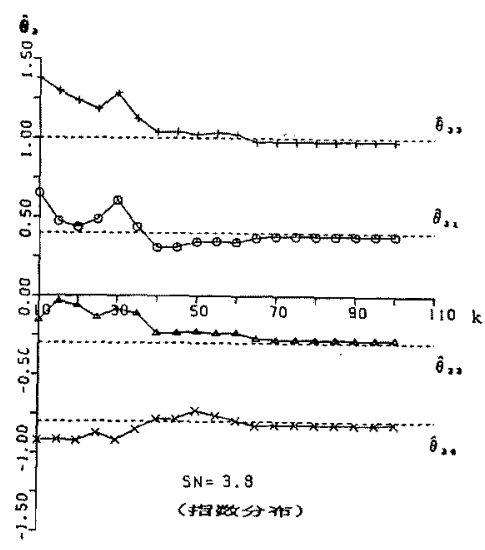

図 4 双線形䒺のパラメー夕推定值の一例

Fig. 4. Estimated parameters of bilinear system.

り、システムとモデルの差異を表わす目安と考えられ る。この一例を表 1 に示す。これによると，そ扎とれ 確率が高い区間の J の值が最も小さく，抙後睡率と $J$ の振舞いが効応して敌り，罗当性がうかがえる。

更に，輁々のSN 比についてシステムの構造を識 別するのに要したデー多数の一例交図 3 に示す。これ より明らかなように SN 比が覀いはどシステムを識別 するために多くのデータを要すると言える。

次に双線形系, Duffing 形桑のシステムと同じ構造 を持つモデルに対するパラメータの推定值の一例老図 4 に示す。これより，デー夕数加增加すると其に，パ ラメータの推定值は真值に㴬近している。これらのこ とは，事後確率の振舞い亡す一致している。

最後に，候補モデルの中にシステムと同じ構造を持 つモデルが旗合，デー夕数が少ない場合は低次の モデルを選定し，データ数が增加するとて長なモデル の中で最低次なあのを選定する傾向がある。

以上のととより，沉関数展開可能な非線形系につい て，钼測維音加指数族の舅合，本方法によりシステム 同定が可能であることが検証された。

\section{5. 結言}

沉関数展關可能な系が指数族の分布に徒う雑音に污 されている場合について，その同定法を考察した。パ ラメータ推定には，最尤法がよく用いられるが，雑音 が指数族の分布に従い，その檤域加半舆限大の場合に は推定が困鞋である。そこで，Kullback の情報量に 基づく評俩最学尊入し，パラメータ推定を行った。次 に，構造の買なる複数個のモデルを侯補しし, Bayes
の定理により备モデルの䉝後確率を求め，ての埪率を

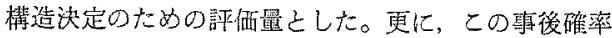

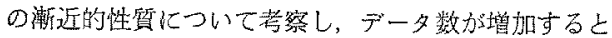

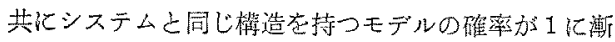
近しシステム棈造を明雄に識別できるととを示し た。

本方法によ机ば，筧測データが此較的少ない場合 は,システムより低次のモデルを選定する傾向があ り，デーダ数の增加に伴いシステムの棈造等明確に識 別することが可能でする。

今後の課題として，候補モデルのより邀切な設定法 を考える必要がある。

(昭和61年8月4日受付)

\section{文献}

(1) E.G. Gilbert: "Functional Expansions for the Response of Nonlinear diffetential systems" IEEE Trans. Automatic Control, AC-22, No. 6, p. 909 (1977)

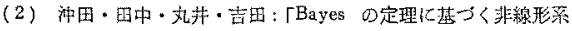

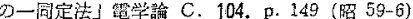

(3) G.E.P. Box \& W. J. Hill: "Discrimination Among Mechanistic Models" THECHNOMETRICS, 9, No. 1, p. 57 (1967)

(4) W. J. Hill \& W. G. Hunter: "A Note on Desings for Model Discrimination: Variance Unknown Case" ibid, 11. No. 2, p. 290 (1969)

(5) L. Maisel (侁藤平八部) : "Probability, Statistics and Randam Prosesses" 檴北出版 (1980)

(6) O. BARNDORFF-NIELSEN : "Information and Exponential Families in Statistical Theory" John Wiley (1978)

(7) Kullback \& Solomon: "Information Theory and Statistics" John Wiley (1959)

(8) R.M. Hawkes and J,B, Moore: "Performance Bounds for Adaptive Estimation" Proc. IEEE, 64, No. 8, p. 1143 (1976)

(9) J. La Salle \& S. Lefschetz (上本稳訳):「乡ヤプノプ方

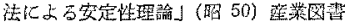

(10) P. Hougaard: "Parametrizations of non-linear models" J. R. Statist. Soc. B. 44 , No. 2 , p. 244 (1982)

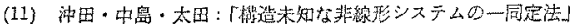

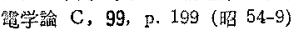

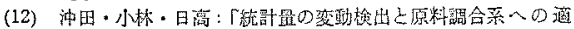

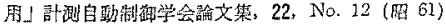

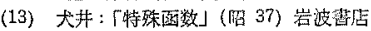

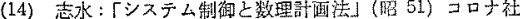

(15) R. V. Churehill (洪四方炏呮) : Operational Mathematics" (1950) 淑圈社

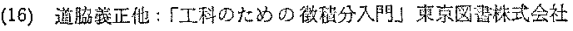
(1978)

\section{付 録}

(13)式の導出 まず，システムとモデルが凮じ棈 造をむつ埸合を考える。

データ数がパラメータ数に比心十分大きい場会, $\hat{\theta}$

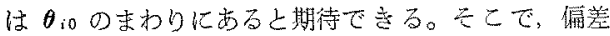
$e_{i}(k)$ を次のように近似する。 


$$
\begin{aligned}
& e_{i}(k) \triangleq y(k)-y_{i}(k) \\
& \fallingdotseq \boldsymbol{h}^{T} \boldsymbol{x}(k)+v(k)-\boldsymbol{h}^{T} \boldsymbol{x}_{\mathbf{i} 0}(k) \\
& +\boldsymbol{h}^{T}\left(\partial \boldsymbol{x}_{i} / \partial \boldsymbol{\theta}_{i}\right)\left(\hat{\boldsymbol{\theta}}_{i}-\boldsymbol{\theta}_{i 0}\right) \\
& =v(k)+w(k)
\end{aligned}
$$

但し， $x_{i 0}(k)$ はパラメータ $\theta_{i 0}$ をむつモデルの状態変 数であり，

$$
\begin{aligned}
& w(k)=\boldsymbol{h}_{i}^{T} C^{T}\left(\hat{\theta}_{i}-\theta_{i 0}\right) \\
& C^{T}=\left(\partial x_{i} / \partial \theta_{i}\right)^{T}
\end{aligned}
$$

で节る。これより(10)式は次のようになる。

$$
\begin{aligned}
& P\left(y(k) \mid i, Y_{k-1}\right) \\
& \quad=\int P w\left(e_{i}(k) \mid v(k), i, Y_{k-1}\right) P v(v(k)) d v(k) \\
& \quad=\int P w\left(e_{i}(k)-v(k) \mid i, Y_{k-1}\right) P v(v(k)) d v(k)
\end{aligned}
$$

ここで, パラメータの推定値 $\hat{\theta}_{i}$ は渐近的に $N\left(\theta_{i 0}\right.$, Ai) の正規分布に従う之みなせるので，Pw(・) む $N\left(0, \sigma_{0}{ }^{2}\right)$ の正嫢分布に従うと考无られる。但し，

$$
\sigma_{\omega}{ }^{2}=\boldsymbol{h}^{T} C^{T} \Lambda_{i} \boldsymbol{C h}
$$

である。また，Pv(・)を次のようにv0のま孙りで近 似する。(ここで，簡単のため， $k$ は省略する。)

$$
\begin{aligned}
P v(v) \doteqdot & \exp \left\{a^{\prime}+b^{\prime}\left(v-v_{0}\right)+c\left(v-v_{0}\right)^{2}+\Delta(v)\right. \\
& \left.+\xi\left(\lambda_{0}\right) \ln v-\phi\left(\lambda_{0}\right)\right\} \\
= & \exp \left\{a+b v+c v^{2}\right\} v^{\xi}\left(\lambda_{0}\right) \exp \{\Delta(v)\}
\end{aligned}
$$

但し,

$$
\begin{aligned}
& a^{\prime}=\phi^{T}\left(\lambda_{0}\right) \tau\left(v_{0}\right) \\
& b^{\prime}=\phi^{T}\left(\lambda_{0}\right)\left(\partial \tau\left(v_{0}\right) / \partial v\right) \\
& c=\phi^{T}\left(\lambda_{0}\right)\left(\partial^{2} \tau\left(v_{0}\right) / \partial v^{2}\right) \\
& a=a^{\prime}-b^{\prime} v_{0}+c v_{0}^{2}-\phi\left(\lambda_{0}\right) \\
& b=b^{\prime}-2 c v_{0}
\end{aligned}
$$

である。なお，(付 2)式の積分を考慮すれば，v。は $e_{i}(k)<0$ の場合は $0, e_{i}(k)>0$ の場合は $e_{i}(k)$ 上する と小い近似加得られる。ここで, $\xi\left(\lambda_{0}\right)=\kappa+\nu(\kappa$ ：自 然数) とし $v\left(\lambda_{\theta}\left(\lambda_{\theta}\right) \exp \{\Delta(v)\}\right.$ 老次の上うに近似する。

$$
\begin{aligned}
& v^{\varepsilon}\left(\hat{\lambda}_{\theta}\right) \exp \{\Delta(v)\} \fallingdotseq v^{*} \sum_{i=0}^{n} \beta_{i} v^{i} \\
& v^{i}=1 / i ! \cdot d^{i} v^{\nu} \exp \{\Delta(v)\} / d v^{i}
\end{aligned}
$$

但し， $n$ は近似の精度に上り決定する。よって, Pv(v) は次式の上うに与党ら机る。
$P v(v)=\exp \left\{a+b v+c v^{2}\right\} \sum_{i=0}^{n} \beta_{i} v^{*+i}$

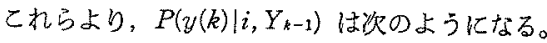
$P\left(y(k) \mid i, Y_{k-1}\right)$

$$
=K^{\prime} \cdot \int_{0}^{\infty} \sum_{i=0}^{n} \beta_{i} v^{n+i} \exp \left\{\omega v^{2}+\rho v\right\} d v
$$

但し,

$$
\begin{aligned}
& K^{\prime}=1 / \sqrt{2 \pi} \sigma_{\omega} \cdot \exp \left\{\left(-e_{i}(k)^{2}+a\right) / 2 \sigma_{\omega}{ }^{2}\right\} \\
& \omega=c+1 / 2 \sigma_{\omega}^{2}, \quad \rho=e_{i}(k) / \sigma_{\omega}^{2}+b
\end{aligned}
$$

である。

また，次の関係が知られている(16)。

$$
\begin{array}{r}
1 /(\mathcal{V} \bar{\pi} g) \cdot \int_{0}^{\infty} v^{m} \exp \left(-v^{2} / 4 g^{2}-s v\right) d v \\
\quad=(-1)^{m} \cdot d^{m} L(s) / d s^{m} \ldots \ldots \ldots \ldots . .
\end{array}
$$

但L,

$$
\begin{aligned}
& L(s)=\exp \left(s^{2} g^{2}\right) E f(s g) \\
& E f(s g) \triangleq \operatorname{erfc}(s g)=2 / \sqrt{\pi} \int_{s g}^{\infty} \exp (-\eta) d \eta
\end{aligned}
$$

である。ここで（付 4)，(付 5 )式において， $\omega=$ $-1 / 4 g^{2}, \rho=-s$ 交対応させると, 次式を得る。

$$
P\left(y(k) \mid i, Y_{k-1}\right)=\text { Con } \cdot \sum_{i=0}^{n} \beta_{i}(-1)^{i} d^{i+\kappa} L(s) / d s^{i+k}
$$
但し,

$$
\text { Con }=\sqrt{\pi} g K^{\prime}
$$

である。更に、ライプニッッの公式より次式を得

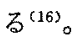

$$
\begin{aligned}
P\left(y(k) \mid i, Y_{k-1}\right) & \\
= & \mathrm{Con} \cdot \sum_{j=1}^{l}{ }_{l} \mathrm{C}_{j}\left\{d^{l-j} \exp \left(s^{2} g^{2}\right) / d s^{t-i}\right\} \\
& \cdot\left\{d^{l} E f(s g) / d s^{l}\right\} \ldots \ldots \ldots \ldots \ldots \text { (付 } 6
\end{aligned}
$$

但し，

$$
\begin{aligned}
\left\{d^{n} \exp \left(s^{2} g^{2}\right) / d s^{n}\right\} & =\exp \left(s^{2} g^{2}\right) g^{n} H_{n}(s g)_{m=1}^{\left[\frac{n}{2}\right]}(-1)^{-m} \\
\left\{d^{n} E f(s g) / d s^{n}\right\}= & -2(-1)^{n} / \sqrt{\pi} \\
& \cdot \exp \left(-s^{2} g^{2}\right) H_{n}(s g)
\end{aligned}
$$

であり, $H_{n}(\cdot)$ は Hermite の多項式である ${ }^{(19)}$ 。

次に、システムとモデルの構造が異なる場合，付 1)式に $\boldsymbol{h}^{T} \boldsymbol{x}(k)-\boldsymbol{h}_{\boldsymbol{i}}{ }^{T} \boldsymbol{x}_{i 0}(k)$ がバィアスとして現われ， てれは $e(k) \triangleq y(k)-y_{i}(k)$ に反映される。よって, 先 の場合と同様㼁諭される。 